\title{
TRANSFORMACIÓN DEL PAISAJE SOCIAL EN ARICA, NORTE DE CHILE: DE PESCADORES ARCAICOS A AGRICULTORES INCIPIENTES
}

\author{
Iván Muñoz O. y Juan Chacama R. ${ }^{1}$
}

\section{$*$ Introducción}

\section{Resumen}

El proceso de cambio de una sociedad de pescadores-recolectores, como los grupos Chinchorro, hacia una sociedad agrícola más seden-

taria, como se ha planteado para las poblaciones Faldas del Morro y Alto Ramírez, no solo implicó un cambio en la estructura social y económica local, sino que conllevó también a cambios en los aspectos ideológicos de estas poblaciones, afectando la manera como el hombre

mantuvo su relación directa con el medio. Así, por ejemplo, la vinculación con determinados hitos geográficos, espacios de extracción de recursos y lugares de asentamientos, jugaron un rol trascendental como ordenadores del territorio. Para analizar dichos cambios retomamos un conjunto de sitios arqueológicos estudiados previamente y que corresponden a poblaciones vinculadas con el período Arcaico Tardío y Formativo de la costa de Arica y sector bajo del valle de Azapa. Se analizan comparativamente tres hitos temporales, los que corresponden a los períodos culturales Arcaico Tardío (2000-1000 AC), Formativo

Temprano (1000-200 AC) y Formativo Tardío (200 AC-500 DC)

Palabras claves: pescadores arcaicos - agricultores incipientes paisaje social.

\begin{abstract}
The change process from fisher-gatherer societies, such as Chinchorro groups, toward sedentary agricultural society, as proposed for the Alto

Ramirez Falda del Morro populations, not only effected their social and economic structure, but also led to changes in the structures of the social organization and the way by which these human groups interacted with their environment. As such, the association between specific geographic landmarks, areas for resource extraction and settlement areas played a main role as territory organizers. In order to study the impact of such aspect $s$ in the local settlement pattern, this article analyses a series of archaeological sites associated to the Late Archaic and Formative period in Arica's coast and the valley of Azapa. To this end, we compared three chronological periods, which correspond to the Late Archaic Cultural Period (2000-1000 AC), Early Formative Period (1000-200 AC), and Late Formative Period (200 AC-500 DC).
\end{abstract}

Key words: Archaic fisher-gatherers - Incipient farmers - Social landscape. Recibido: septiembre 2009. Aceptado: diciembre 2011.
Estudios recientes desarrollados por los autores de este manuscrito en torno a las sociedades Formativas señalan que, durante el proceso de cambio vivido por los pescadores en tránsito a la agricultura (1500-500 AC), no solamente el hombre fue partícipe de esta transformación gradual, sino que intervino activamente en el escenario natural como un agente integrado as sistema ecológico. En los aproximadamente 1.000 años que dura este proceso de transición, observamos diversas escalas de cambio, que culminan en un conjunto de estructuras funerarias elevadas, asociadas al culto a los ancestros fundadores, además de servir como estructuras demarcatorias de territorios en relación con los hídricos, fundamentales para el desarrollo agrícola. Considerando la magnitud de esos cambios, en el presente estudios pretendemos analizar de manera reflexiva el rol que habrían alcanzado los pescadores de la costa de Arica en el difícil y complejo proceso que fue el tránsito hacia la agricultura. Dicha complejidad ha sido discutida entre otros por Núñez (1969, 1983, 1989) y Núñez y Santoro (2011), al señalar la relación entre los grupos costeros y las primeras sociedades agrícolas aldeanas en los valles occidentales, a través del uso de materias primas y de la presencia de tecnologías para la pesca y caza marina en las sociedades agrícolas, lo que sugiere una continuidad de rasgos culturales entre costa e interior. Este planteamiento ha sido corroborado por Santoro (1980a, 1982), Muñoz (1980, 1989, 2004, 2011a), Standen et al. (2004), entre otros, quienes ha señalado que los pescadores arcaicos serían el soporte cultural sobre el cual se asentaron las poblaciones agrícolas tempranas en los valles costeros de Arica a partir del 1000 AC.

\footnotetext{
1.Departamento de Antropología, Universidad de Tarapacá, Arica, CHILE.Email: imunoz@uta.cl, jchacama@uta.cl
} 
Nuestra propuesta - si bien tiene como base la discusión de un modelo local de desarrollo a partir del análisis de un conjunto de sitios de los períodos Arcaico y Formativo, emplazados en el litoral de Arica y sector bajo del valle de Azapa-, tiene la particularidad de que en este análisis integramos el entorno como un factor importante dentro del paisaje social, cuya estrategia de desarrollo apuntaba gradualmente hacia la explotación agrícola de los valles dentro de un ordenamiento del espacio ocupacional. El análisis de las evidencias nos permite plantear un sistema de asentamientos que estaría dado por, a) un proceso de conquista tecnológica y asentamientos con intenso ceremonialismo en torno a la ritualidad de la muerte; b) un proceso experimental que involucró espacios de valle bajo y costa donde se dio la explotación de recursos hídricos y terrenos vinculados a las primeras prácticas agrícolas; y c) la ocupación progresiva y permanente de los valles una vez que se logran ciertas líneas productivas en cuanto a los cultivos.

\section{* Reflexiones teóricas para el análisis DE UNA SOCIEDAD EN PROCESO DE CAMBIO}

Para discutir el proceso social vivido por las poblaciones de pescadores en tránsito hacia la agricultura, hemos tomado en nuestro modelo de análisis el aporte de la arqueología del paisaje, que involucra al hombre y los cambios que hizo en su entorno, en el contexto de su ordenamiento y percepción del espacio. El paisaje, según Criado (1999), se concibe como un producto social constituido por el espacio físico natural, como marco medioambiental de la acción humana; el espacio social o medio construido culturalmente, donde se producen las relaciones entre individuos y grupos; y el espacio pensado o medio simbólico, que permite ordenar y dar sentido y significancia a la apropiación humana de la naturaleza. Según Bourdieu (1999), las personas activamente ordenan, transforman, se identifican y memorizan el paisaje a través del contacto; por lo tanto, el sentido del lugar y su compromiso con el mundo que las rodea invariablemente dependen de sus propias situaciones sociales, históricas y culturales.

La producción de bienes utilizando los distintos recursos que ofrece el medio, sustenta la hipótesis de la optimización que las poblaciones arcaicas del norte de Chile habrían hecho de su entorno. Esta situación implica que conocieron muy bien el medio, tanto costero (litoral), como la desembocadura de ríos y valles circundantes, lo que les permitió hacer un uso racional de la explotación de los recursos. Sin embargo, el conocimiento del espacio no se manifiesta solo en lo económico, con la explotación de los recursos para desarrollar tecnologías de subsistencia, sino también en la importancia que habrían tenido distintos hitos geográficos en el plano ideológico de estas tempranas sociedades. En el caso de los pescadores y recolectores marinos, asentarse a vivir en el valle de Azapa implicó una relación directa con hitos naturales como las vertientes, humedales y la vegetación, que más allá de la relación por apropiación, estructuraron la organización basal sobre la cual se ordenó el espacio ocupado (Muñoz 2010). Desde esta óptica, la construcción de basurales con formas de montículos en la costa durante el período Arcaico, así como la construcción de túmulos ceremoniales en el período Formativo, sugiere la idea que estas poblaciones consideraron en sus asentamientos la forma de los cerros, imitación que resume la importancia del paisaje natural en la cosmovisión de los grupos tempranos de pescadores del litoral de Arica.

\section{* Objetivo y metodología}

El presente estudio tiene como objetivo analizar cómo se organizó, a partir de la apropiación de los recursos, el ordenamiento del espacio ocupacional por parte de los pescadores a fines del período Arcaico y durante el período Formativo, partiendo de la base que éste se habría concentrado inicialmente en la franja costera y posteriormente se desplazó hacia el valle de Azapa, en la medida que el proceso agrícola ganó importancia.

Para llevar a cabo nuestra estudio, desde un punto de vista metodológico, se propuso una reevaluación de los sitios excavados, analizando su materialidad (componentes culturales de cada uno de ellos) y las relaciones en cuanto a distancia y visibilidad de dichos sitios -asentamientos- con los recursos hídricos (vertientes y humedales), fundamentales para determinar el espacio de asentamiento.

Las reevaluaciones y prospecciones llevadas a cabo permitieron trazar mapas de ubicación en tres cortes tem- 


\begin{tabular}{|c|c|c|}
\hline Áreas geográficas & Sector & Eco zonas \\
\hline Cordillera de la Costa & & Formación de cerros; el morro de Arica \\
\hline $\begin{array}{c}\text { Planicie desértica } \\
\text { (depresión intermedia) }\end{array}$ & & \\
\hline \multirow[b]{2}{*}{ Sistema de tributarios } & Quebrada del Diablo (ladera norte) & \\
\hline & $\begin{array}{c}\text { Quebrada de las Llocllas, quebrada de Acha, bajada } \\
\text { del cerro La Cruz (ladera sur) }\end{array}$ & \\
\hline \multirow{3}{*}{ Litoral } & \multirow[t]{2}{*}{ Sur } & $\begin{array}{c}\text { Costa rocosa, refugios naturales: cueva de la Capilla } \\
\text { y Anzota }\end{array}$ \\
\hline & & Terraza marina \\
\hline & Norte & Costa de arena (playa) \\
\hline \multirow{11}{*}{ Valle de Azapa } & \multirow{5}{*}{ Tramo costero } & $\begin{array}{l}\text { Ladera norte, formación de peñones y cerros } \\
\text { aislados; cerro San Lorenzo, cerro Sombrero, etc. }\end{array}$ \\
\hline & & $\begin{array}{l}\text { Ladera sur irregular con formación de cerros } \\
\text { aislados: Chuño }\end{array}$ \\
\hline & & Terrazas fluviales bajas \\
\hline & & Caja del río \\
\hline & & Cauce del río \\
\hline & \multirow{6}{*}{ Tramo bajo } & Ladera norte con terraza fluvial alta \\
\hline & & Ladera sur \\
\hline & & Terrazas fluviales bajas \\
\hline & & Caja del río \\
\hline & & Cauce del río \\
\hline & & Vertientes en zonas de interfluvio \\
\hline
\end{tabular}

Tabla 1. Espacios geográficos y eco-zonas de la costa de Arica y valle de Azapa.

porales: Arcaico Tardío (2000-1000 AC), Formativo Temprano (1000-200 AC) y Formativo Medio (200 AC-500 DC), cada uno de ellos respaldados por un conjunto de sitios arqueológicos y sus correspondientes dataciones absolutas. El análisis emprendido nos ha permitido visualizar de forma clara el dinámico proceso de construcción y cambio del paisaje social, en este caso de sociedades muy dependientes del mar en cuanto a su territorialidad y que lentamente fueron adentrándose a los valles para asentarse, de preferencia en los sectores con recursos de agua permanente.

\section{* Espacio geográfico}

Para el caso de nuestro estudio, el espacio geográfico está constituido por el litoral de Arica y el sector bajo del valle de Azapa (Tabla 1).
El litoral de Arica y sus ecozonas. Dos grandes ecozonas se identifican en la costa de Arica en términos longitudinales según Keller (1946) y Tapia (2012): la costa rocosa y la costa arenosa. La costa rocosa -ubicada al sur del morro de Arica-, se caracteriza por estar estrechamente adosada a la cordillera de la Costa; en algunos tramos la distancia desde la línea de mar a los faldeos cordilleranos, no alcanza los $50 \mathrm{~m}$. Por su estrecho vínculo a la mencionada cordillera, se trata de una costa predominantemente rocosa, con escasas playas y abruptos acantilados. Existen refugios naturales como las cuevas de la Capilla y Anzota, la primera con evidencia de ocupación por pescadores a fines del período Arcaico y durante el Formativo Temprano. Acorde con dichas características, esta zona presenta abundante cantidad de moluscos de hábitat rocoso que se alimentan de algas y microorganismos de roca. En esta costa se hallan los mayores y más antiguos asentamientos humanos prehispánicos en la 


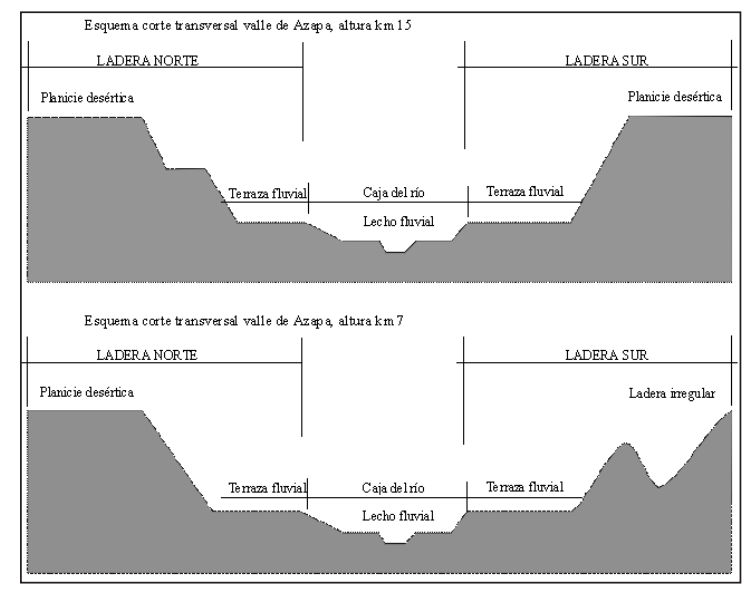

Figura 1. Dibujo esquemático del corte transversal del valle de Azapa a la altura de los kilómetros 15 y 7.

región, tales como Quiani, La Capilla, Playa Miller y El Morro de Arica.

La costa arenosa, ubicada al norte del morro de Arica, corresponde a una gran bahía resultado del hundimiento de la cordillera de la Costa a la altura del morro, que emerge nuevamente en la proximidades de la desembocadura del valle del Caplina, en el extremo sur del Perú. Esta bahía se visualiza como una gran playa de arena donde se encuentran principalmente especies de bivalvos enterrados en la arena y peces de orilla que dieron sustento a las antiguas poblaciones Chinchorro.

El valle de Azapa y sus ecozonas (Figura 1). La primera descripción histórica del valle de Azapa la tenemos de Vásquez de Espinoza, quien en 1628-1629, al bajar desde la cordillera de los Andes en dirección al océano Pacífico, describe dicho valle con sus aguas que drenan en sus arenales, dando una imagen de un valle seco que es más bien un pedregal continuo con afloramientos de (ojos de) agua cada cierto trecho, en los cuales se producen ciénagas y humedales, constituyéndose en potenciales espacios de desarrollo agrícola. Este paisaje se mantuvo hasta la canalización del río Lauca, a mediados del siglo pasado, el cual atraviesa y riega actualmente el valle, cambiando su configuración de lo que fue originalmente.

Desde los inicios de la explotación agrícola, el pescador ocupó el sector bajo del valle de Azapa que va desde la desembocadura del río San José hasta el kilómetro 14. En este espacio encontramos una serie de ecozonas e hitos geográficos que el hombre aprovechó para asentarse. En primer lugar, tenemos las terrazas fluviales a ambos lados de la caja del río que se despliegan en dirección este-oeste, constituyendo extensas planicies delimitadas por una parte por la caja del río y por otra por las laderas de los cerros. Estas planicies deben haber cambiado su forma y sobre todo su ancho, dependiendo de los diferentes cursos que el río ha tomado en el transcurso de varios milenios. Registros de tempranos cementerios y restos de campamentos sugieren que fueron los espacios más aprovechados por los tempranos agricultores para construir sus asentamientos.

En segundo lugar, tenemos la caja y lecho del río, que son los sectores más cambiantes de todas las ecozonas mencionadas. Compuestos por un fondo pedregoso cubierto de grandes cantos rodados, la caja y lecho del río da cuenta del arrastre fluvial de gran cantidad de material desde las zonas más altas, y son marcados por diferentes surcos que dan cuenta de los continuos cambios del cauce fluvial del río San José. Sin embargo, al no hallarse vestigios de terrazas de cultivos, hemos sugerido un sistema más simple donde los recursos de aguas subterráneas habrían sido conducidos por medio de acequias a terrenos planos cercanos a la caja del rio San José. Debemos señalar que este sistema fue descrito para el valle de Azapa por Frezier en 1772 (citado por Dagnino 1909) al describir plantaciones del maíz y ají.

En tercer lugar se hallan las vertientes, afloramientos de agua que se ubican preferentemente en los sectores de intersección del valle de Azapa con sus tributarios (quebrada del Diablo, quebrada de las Llocllas, quebrada de Acha, bajada del cerro La Cruz). La diferencia del subsuelo rocoso entre ambas situaciones produciría bolsones de aguas que escurren por los niveles freáticos, provocando respectivos afloramientos (Tapia, 2012). Estos recursos jugaron un rol trascendental en la explotación agrícola que el pescador hizo del valle de Azapa; sin ellos, no hubiese sido posible la conquista agraria, por lo tanto, debieron haber constituido el recurso natural más preciado por los tempranos agricultores, provocando tensiones y conflicto entre las poblaciones nativas locales. Asimismo, el ecosistema vegetal, formado a partir de estos brotes de agua, permitió a los pescadores en tránsito a 


\begin{tabular}{|c|c|c|c|c|c|c|}
\hline Sitio & Rango temporal & $\begin{array}{c}\text { Espacio } \\
\text { geográfico }\end{array}$ & & Eco zona & Tipo & Referencia \\
\hline $\begin{array}{l}\text { Morro } 1 / 6 \\
(\text { Mo } 1 / 6)\end{array}$ & $\begin{array}{c}2320 \mathrm{AC}-1905 \\
\mathrm{AC}\end{array}$ & Litoral & Costa rocosa & Ladera norte morro de Arica & Cementerio & Focacci y Chacón 1989 \\
\hline $\begin{array}{l}\text { Morro } 1 / 5 \\
(\text { Mo } 1 / 5)\end{array}$ & $2170 \mathrm{AC}$ & Litoral & Costa rocosa & Ladera norte morro de Arica & Cementerio & Guillén 1995 \\
\hline $\begin{array}{l}\text { Quiani } 7 \\
\text { (Qu. 7) }\end{array}$ & $\begin{array}{c}1640 \mathrm{AC}-1290 \\
\mathrm{AC}\end{array}$ & Litoral & Costa rocosa & $\begin{array}{l}\text { Ladera media cordillera de la } \\
\text { Costa. Vertiente }\end{array}$ & Cementerio & Dauelsberg 1974 \\
\hline $\begin{array}{l}\text { La Capilla1 } \\
\text { (LaCap. 1) }\end{array}$ & $1720 \mathrm{AC}-840 \mathrm{AC}$ & Litoral & Costa rocosa & $\begin{array}{l}\text { Ladera baja cordillera de la } \\
\text { Costa }\end{array}$ & $\begin{array}{l}\text { Cueva con } \\
\text { pictografías }\end{array}$ & $\begin{array}{l}\text { Muñoz y Chacama 1982; } \\
\text { Chacama y Muñoz 1991 }\end{array}$ \\
\hline
\end{tabular}

Tabla 2. Rango temporal y ubicación espacial de los asentamientos estudiados del período Arcaico Tardío.

la agricultura recolectar una variedad de plantas con las cuales confeccionaron vestimentas, utensilios y esteras para cubrirse.

\section{$\uparrow$ Los actores sociales}

Con el propósito de lograr nuestro objetivo y obtener una mejor visión de éste, compararemos el uso y manejo del espacio por parte de las poblaciones del período Arcaico Tardío (2000-1000 AC) con las poblaciones del período Formativo Temprano (1000-200 AC) y del período Formativo Tardío (200 AC-500 DC). Antes de caracterizar cada uno de estos hitos temporales, es necesario señalar que las fechas de inicio y término de cada uno de estos períodos, así como muchas de sus características particulares, son aspectos puramente metodológicos que nos permiten observar separadamente cada uno de los segmentos temporales propuestos. Dentro de un proceso cultural continuo, las dinámicas culturales que se suceden dentro de él son graduales. Por tanto, los cambios culturales sucedidos no son abruptos ni cultural ni temporalmente.

Período Arcaico Tardío (Tabla 2). Se caracteriza como el período cultural situado entre el año 2000 y $1000 \mathrm{AC}$, correspondiente a la época final de la tradición de pescadores Chinchorro. Durante ese período ocurren importantes cambios culturales, entre ellos el del patrón de enterramiento: desaparece la momificación artificial y posición extendida de los cuerpos, que se remplaza por una posición decúbito lateral con piernas flexionadas. Los entierros son depositados en fosas y incorpora como marcador de entierro un madero en posición vertical. Esta nueva forma de enterrar a sus muertos refleja evidentemente cambios en el nivel ideológico por parte de los grupos costeros.

Aunque el sustento económico siguió teniendo su base en la pesca y recolección de productos marítimos, en este período se observan los primeros intentos de aproximación a una economía con base agrícola. Una calabaza (Curcubita sp.) proveniente del sitio Quiani 7 (Dauelsberg 1974) y restos de yuca o mandioca (Manihot esculenta) provenientes del sitio La Capilla I (Muñoz 1982) serían indicadores de estas primeras prácticas agrícolas.

Asimismo, a través del ajuar mortuorio se aprecia una mayor tendencia al uso de adornos corporales como collares y tocados cefálicos (turbantes), cuyo origen se remonta al Arcaico Temprano. A estas incorporaciones tecnológicas y manifestaciones de complejidad social se agrega la introducción del complejo alucinógeno, lo que podría sugerir una temprana ingesta de sustancias psicoactivas en las poblaciones de pescadores arcaicos del extremo norte de Chile, o una activa interrelación de intercambio de bienes de prestigio con grupos foráneos.

Periodo Formativo. Según Muñoz (1989), el elemento cultural más emblemático de este período fue sin duda el paso de una sociedad de pescadores-recolectores a una sociedad con énfasis en una economía agraria. No obstante lo anterior, otros aspectos no menos importantes caracterizan a este período en los valles occidentales. Uno de ellos es la llegada de objetos provenientes probablemente de la cuenca circumlacustre del Titicaca. Ambos 
Iván Muñoz O., JuAn Chacama R.

\begin{tabular}{|c|c|c|c|c|c|c|}
\hline Sitio & Rango temporal & Espacio geográfico & \multicolumn{2}{|c|}{ Eco zona } & Tipo & Publicado \\
\hline Azapa 70 & $490-70 \mathrm{AC}$ & Valle & Tramo bajo & $\begin{array}{c}\text { Terraza fluvial } \\
\text { confluencia } \\
\text { tributario/aguada }\end{array}$ & Túmulo & $\begin{array}{c}\text { Focacci y Erices 1972- } \\
1973\end{array}$ \\
\hline $\begin{array}{c}\text { Azapa 71 } \\
\text { Fase Azapa }\end{array}$ & $905-470 \mathrm{AC}$ & Valle & Tramo bajo & $\begin{array}{c}\text { Terraza fluvial } \\
\text { confluencia } \\
\text { tributario / aguada }\end{array}$ & Cementerio & Santoro 1980a, 1980b \\
\hline Playa Miller 7 & $530 \mathrm{AC}$ & Litoral & Costa rocosa & Ladera baja & Cementerio & Focacci 1974 \\
\hline Morro 2 & $800-480 \mathrm{AC}$ & Litoral & Costa rocosa & $\begin{array}{c}\text { Desembocadura } \\
\text { valle / aguada? }\end{array}$ & Cementerio & Dauelsberg 1985 \\
\hline La Capilla 1 & $840 \mathrm{AC}$ & Litoral & Costa rocosa & $\begin{array}{c}\text { Acantilado } \\
\text { cordillera de la costa }\end{array}$ & Cueva & Muñoz y Chacama 1982 \\
\hline Azapa 14 & $\begin{array}{c}\text { 690 AC - } \\
\pm 500 \mathrm{DC}\end{array}$ & Valle & Tramo bajo & $\begin{array}{c}\text { Terraza fluvial } \\
\text { confluencia } \\
\text { tributario }\end{array}$ & Cementerio & Santoro 1980b \\
\hline
\end{tabular}

Tabla 3. Sitios del período Formativo Temprano y su ubicación espacial.

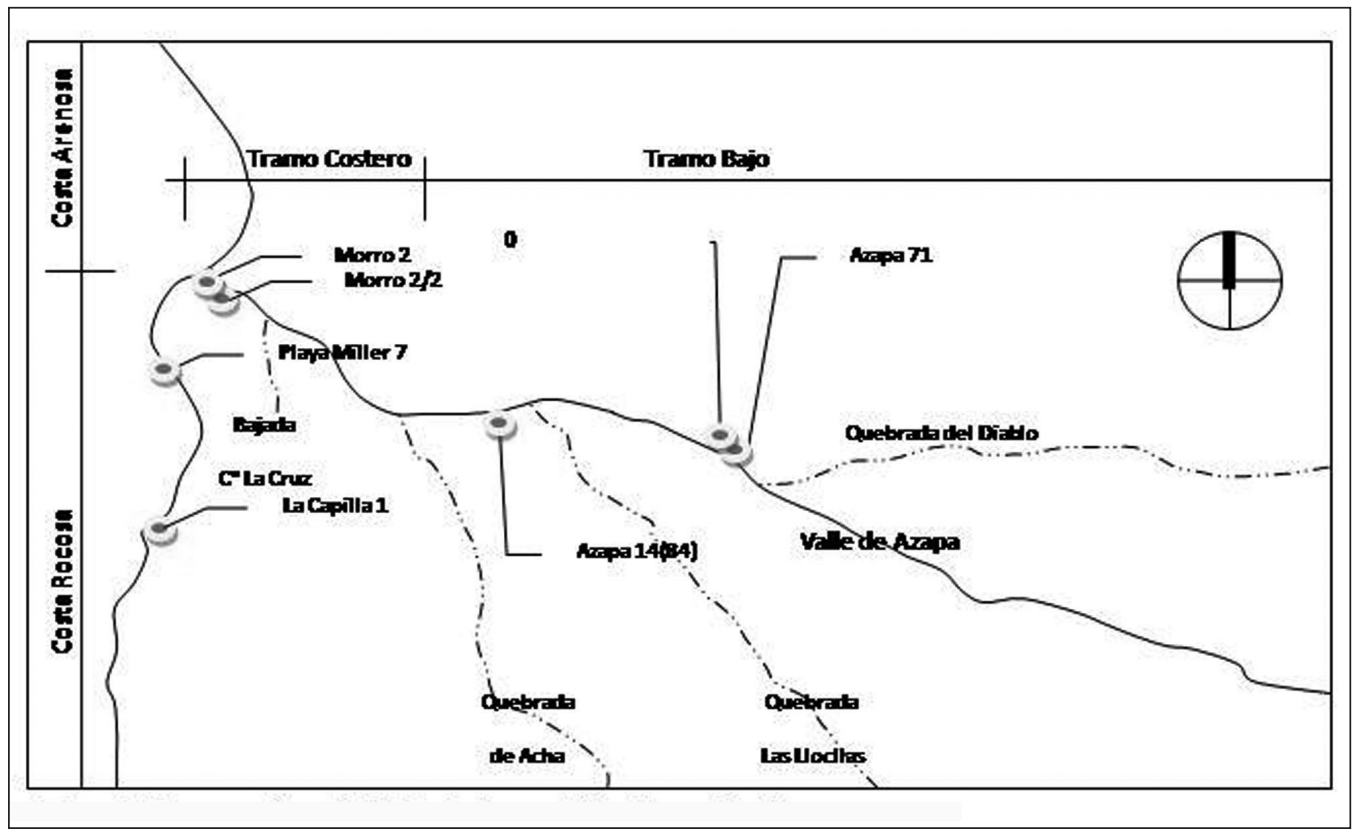

Figura 2. Ubicación geográfica de los sitios del Formativo Temprano.

aspectos han llevado a proponer dos modelos culturales para comprender dicho período: el primero hace hincapié en un difusionismo altiplánico caracterizado por aportes culturales y genéticos durante la fase Alto Ramírez como factor preponderante en la formación de una temprana complejidad social, postura que ha sido sostenida por Ri- vera (1980, 1987, 1994, 1995-1996). El segundo reconoce un proceso conducido por las poblaciones locales, es decir los pescadores, en un contexto paulatino y progresivo que se inicia a partir del primer milenio AC (Núñez 1983; Muñoz 1987, 1989; Santoro 1982, 2000; Standen et al. 2004; Sutter 2000, 2006). 
El período Formativo abarca aproximadamente 1.500 años de duración, pero para efectos de este trabajo, lo hemos dividido en dos grandes momentos culturales: Formativo Temprano y Formativo Tardío. El primero se encuentra situado entre 1000 y $200 \mathrm{AC}$, fecha que da cuenta de las últimas manifestaciones de la tradición Chinchorro y del aparecimiento de la cerámica y la metalurgia entre otros contextos diagnósticos. El Formativo Tardío se expande desde el año 200 AC hasta el 500 DC, fecha que da cuenta de la consolidación del período aldeano en los valles así como también de la gran proliferación de túmulos funerarios, construcciones monumentales hechas de tierra y fibra vegetal, representativas de este momento cultural.

Período Formativo Temprano (Tabla 3, Figura 2). Este período está definido por un conjunto de sitios arqueológicos cuya materialidad indica una economía con fuerte base marítima. A diferencia de los sitios del período Arcaico Tardío, que se ubicaban en el litoral, éstos comienzan a ocupar, además, múltiples espacios de valle, distribuyéndose en áreas diversas que van desde el litoral mismo hasta $12 \mathrm{~km}$ valle arriba, en el sitio Azapa 71.

Paralelo al proceso de experimentación agrícola que estas poblaciones llevan a cabo y, desde un punto de vista socio-tecnológico, estas poblaciones incorporan el uso de objetos en metalurgia (Santoro 1980a, 1980b), los primeros tiestos de cerámica (Santoro 1982), el conocimiento de la técnica del telar y el uso de la fibra de camélido teñida (Rivera 1980), tecnologías propias de grupos humanos en proceso de sedentarización en torno a áreas de cultivo. Junto a este proceso, se encuentran las primeras evidencias de monumentalidad, reflejada en los así llamados túmulos funerarios (p.e., Azapa 70).

En resumen, el Período Formativo Temprano corresponde a poblaciones de origen costero que están incursionando en espacios de valles, generando un proceso de experimentación agrícola, sedentarización y expansión del desarrollo tecnológico, actividades que serán el germen del proceso aldeano regional.

Periodo Formativo Tardío (Tabla 4, Figura 3). Corresponde a un momento de consolidación del proceso agrícola en los valles costeros, como el caso del valle de Azapa. El conjunto de sitios arqueológicos representativos de este momento se encuentra en su totalidad disperso a lo largo del valle. Al parecer, las relaciones de las poblaciones de valle con las de tierras altas comienzan a tener una interacción más sistemática, introduciéndose en los grupos locales nuevas tecnologías, así como también nuevos conceptos ideológicos, como el culto al cráneo, visibilizado en las cabezas trofeo y en las imágenes iconográficas del sacrificador. Del mismo modo, se aprecian también las primeras imágenes de un rostro irradiado, el cual posteriormente será tema central en la iconografía del horizonte cultural Huari-Tiawanaku. Por otra parte, es durante este momento donde se produce una mayor transformación del paisaje social con un gran despliegue de túmulos funerarios que impactan el paisaje del valle (Romero et al. 2004; Muñoz y Zalaquett 2011), encontrándose en determinados sectores del valle núcleos con más de 30 estructuras monumentales de túmulos.

\section{$*$ Discusión}

Antes de discutir la apropiación y ordenamiento del espacio ocupacional en la costa y en el valle, analizaremos las probables razones que pudiesen haberse dado para que las poblaciones de pescadores se fueran a vivir al valle. Según Chacama y Muñoz (2012), un primer supuesto señala que el cambio cultural en cuestión fue un proceso lento y gradual, que tardó varios siglos. El actual estado de avance de la investigación nos permite complementar ese supuesto y visualizar algunas de las causas que influyeron en el cambio cultural de pescadores a agricultores, las que pueden atribuirse a factores de tipo endógeno y factores de tipo exógeno.

Factores endógenos. El continuo proceso de incursión a los valles llevado a cabo por las poblaciones de pescadores arcaicos a través de varios milenios les permitió comprender el ciclo de las plantas y experimentar con él, para finalmente optar por un modo de vida agrario. La información arqueobotánica para los valles de Arica reconoce la identificación de una serie de semillas y frutos de algodón, camote, calabaza y mandioca desde el período Arcaico Tardío, ampliándose a un mayor número de especies como maíz, quínoa, yuca, poroto, ají y achira durante el período Formativo (Muñoz 2004). Sin embargo, su uso alimentario está determinado por el análisis de muestras 
Iván Muñoz O., JuAn Chacama R.

\begin{tabular}{|c|c|c|c|c|c|c|c|}
\hline \multicolumn{2}{|c|}{ Sitio } & Rango temporal & Espacio geográ-fico & \multicolumn{2}{|c|}{ Eco zona } & Tipo & $\begin{array}{c}\text { Investigado / } \\
\text { Publicado }\end{array}$ \\
\hline \multicolumn{2}{|c|}{ Morro 2} & $800 \mathrm{AC}-400 \mathrm{AC}$ & Valle & Tramo costero & $\begin{array}{c}\text { Desembocadura valle/ } \\
\text { humedal }\end{array}$ & Cementerio & Dauelsberg 1985 \\
\hline \multicolumn{2}{|c|}{ Morro 3} & & Valle & Tramo costero & $\begin{array}{c}\text { Desembocadura valle/ } \\
\text { humedal }\end{array}$ & Túmulos & No investigado \\
\hline \multicolumn{2}{|c|}{$\begin{array}{c}\text { Azapa } 24 \\
\text { Co San Miguel }\end{array}$} & & Valle & Tramo costero & $\begin{array}{l}\text { Cerro isla en } \\
\text { interfluvio }\end{array}$ & Túmulos & Muñoz y Rocha 2011 \\
\hline \multicolumn{2}{|c|}{ Azapa 21} & & Valle & Tramo bajo & Terraza fluvial valle & Túmulos & Muñoz, Zalaquett 2011 \\
\hline \multicolumn{2}{|c|}{ Azapa 22} & & Valle & Tramo bajo & Terraza fluvial valle & Túmulos & Muñoz y Rocha 2011 \\
\hline \multicolumn{2}{|c|}{ Azapa 14(84) } & $\begin{array}{l}690 \mathrm{AC}- \\
\pm 500 \mathrm{DC}\end{array}$ & Valle & Tramo bajo & $\begin{array}{c}\text { Terraza fluvial } \\
\text { tributario/vertiente }\end{array}$ & Cementerio & Santoro $1980 \mathrm{a}, 198 \mathrm{ob}$ \\
\hline \multicolumn{2}{|c|}{ Azapa 122} & $330-90 \mathrm{AC}$ & Valle & Tramo bajo & $\begin{array}{c}\text { Terraza fluvial } \\
\text { tributario/vertiente }\end{array}$ & Túmulos & $\begin{array}{c}\text { Muñoz 1980, } 1983 \text {, } \\
1987\end{array}$ \\
\hline \multicolumn{2}{|c|}{ Azapa 17} & & Valle & Tramo bajo & $\begin{array}{c}\text { Terraza fluvial } \\
\text { tributario/vertiente }\end{array}$ & Túmulos & Muñoz y Rocha 2011 \\
\hline \multicolumn{2}{|c|}{ Azapa 147} & & Valle & Tramo bajo & $\begin{array}{c}\text { Terraza fluvial } \\
\text { confluencia tributario } \\
\text { / vertiente }\end{array}$ & Túmulos & No investigado \\
\hline \multicolumn{2}{|c|}{ Azapa 80} & & Valle & Tramo bajo & $\begin{array}{c}\text { Terraza fluvial } \\
\text { confluencia tributario } \\
\text { / vertiente }\end{array}$ & Túmulos & Muñoz y Rocha 2011 \\
\hline \multicolumn{2}{|c|}{ Azapa 12} & & Valle & Tramo bajo & Ladera/vertiente & Túmulos & $\begin{array}{c}\text { Muñoz } 1986 \text { y Muñoz } \\
\text { y Rocha } 2011\end{array}$ \\
\hline \multicolumn{2}{|c|}{ Azapa 83} & $500-700 \mathrm{DC}$ & Valle & Tramo bajo & $\begin{array}{c}\text { Terraza fluvial } \\
\text { tributario/vertiente }\end{array}$ & Aldea & Rivera 1987 \\
\hline \multicolumn{2}{|c|}{ Azapa 115} & $1-300 \mathrm{DC}$ & Valle & Tramo bajo & $\begin{array}{c}\text { Terraza fluvial/ } \\
\text { vertiente }\end{array}$ & Cementerio & $\begin{array}{c}\text { Focacci 1983; Muñoz } \\
\text { 1995-1996 }\end{array}$ \\
\hline \multicolumn{2}{|c|}{ Azapa 75} & $300 \mathrm{DC}$ & Valle & Tramo bajo & $\begin{array}{c}\text { Terraza fluvial/ } \\
\text { vertiente }\end{array}$ & Cementerio & $\begin{array}{c}\text { Focacci 1983; Muñoz } \\
1995-1996\end{array}$ \\
\hline \multirow{5}{*}{$\begin{array}{c}\text { Azapa } \\
70\end{array}$} & T.1 & \multirow{5}{*}{$500-50 \mathrm{AC}$} & \multirow{5}{*}{ Valle } & \multirow{5}{*}{ Tramo bajo } & \multirow{5}{*}{$\begin{array}{c}\text { Terraza fluvial/ } \\
\text { vertiente }\end{array}$} & \multirow{5}{*}{ Túmulos } & $\begin{array}{c}\text { Focacci y Erices } \\
1972-1973 \\
\end{array}$ \\
\hline & $\mathrm{T} .3$ & & & & & & $\begin{array}{c}\text { Muñoz } 1980,1983 \text {, } \\
1987\end{array}$ \\
\hline & T.6 & & & & & & \\
\hline & T.7 & & & & & & Muñoz 1995-96 \\
\hline & T.8 & & & & & & Romero et al. 2004 \\
\hline \multirow[b]{2}{*}{ Azapa 67} & T.2 & & & & Terraza fluvial & & \\
\hline & T. $2^{\mathrm{a}}$ & & Valle & Tramo bajo & $\begin{array}{c}\text { confluencia tributario } \\
\text { /vertiente }\end{array}$ & Túmulos & Muñoz y Rocha 2011 \\
\hline \multicolumn{2}{|c|}{ Azapa 117} & & Valle & Tramo bajo & $\begin{array}{c}\text { Terraza fluvial } \\
\text { confluencia tributario }\end{array}$ & Túmulos & No investigado \\
\hline
\end{tabular}

Tabla 4. Sitios del período Formativo Tardío y su distribución espacial.

de coprolitos humanos, identificándose restos de epidermis de porotos y maíz, semillas de ají (chile) y hojas de plantas monocotiledóneas, posiblemente cebollín. Estas muestras fueron tomadas de los túmulos Az-122 y Az-70 (Muñoz 1987), lo que demuestra que durante el período Formativo dichas plantas eran consumidas por las poblaciones azapeñas.

La evidencia biológica. Rothhammer y Santoro (2001), aplicando técnicas de análisis multivariado sobre un conjunto de medidas craneométricas, sugieren que el poblamiento ancestral costero habría dado origen a los habitantes de los valles (alrededor de $1500 \mathrm{AC}$ ). A éste se le habría sumado el aporte de cierto flujo génico de grupos reducidos de población altiplánica que arriba a los valles costeros, el cual no constituiría una migración a gran escala.

Por su parte, Sutter (2006), sobre la base de estudios relacionados con distancias biológicas en rasgos métricos dentales, señala bajos niveles de flujo génico en las poblaciones prehispánicas del valle de Azapa, vinculados a poblaciones altiplánicas. Dicho resultado sugiere que fueron los grupos costeros de tradición arcaica los que iniciaron el poblamiento agrario en los valles bajos (Sutter 2006). 


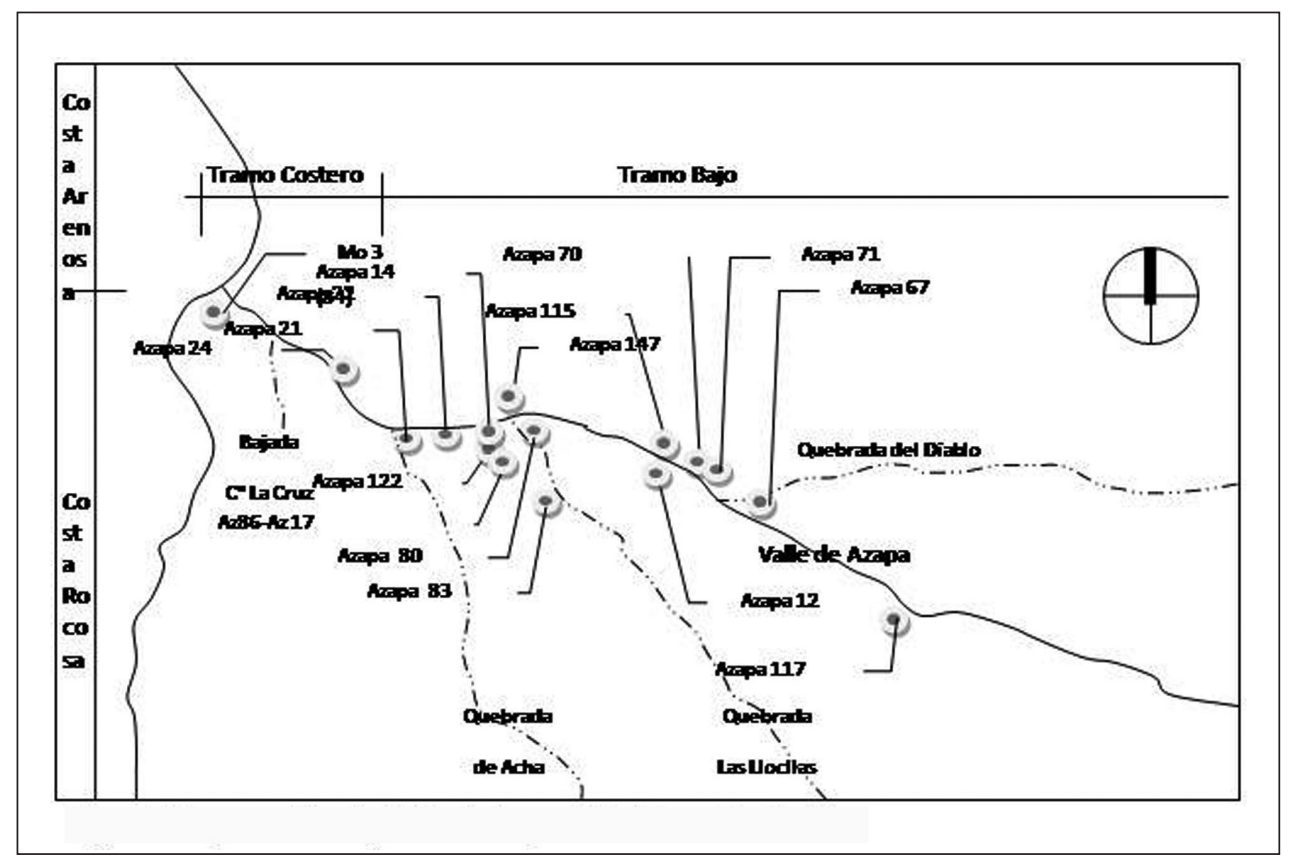

Figura 3. Ubicación geográfica de los sitios del Formativo Tardío.

Violencia y aumento demográfico. Aun cuando el cálculo demográfico de las poblaciones prehispánicas es un tema poco estudiado, es posible aproximarse a éste a través de observaciones indirectas, como por ejemplo la evidencia de violencia entre las poblaciones prehispánicas del extremo norte de Chile. Standen y colaboradores (2007) han percibido que durante el período Formativo se dieron casos de extrema violencia colectiva (sitio Az-146), de una manera que no había sido registrada para épocas anteriores. Este nivel de violencia pudo tener como causa probables disputas por recursos escasos como las vertientes, que proveían los recursos hídricos indispensables para una sociedad agrícola inicial en vías de sedentarización (Standen et al. 2007). Por otra parte, si bien el recurso hídrico es un bien escaso en el valle de Azapa, dicha escasez pudo también verse presionada por un aumento demográfico.

De ser válido el razonamiento y supuesto anterior, podríamos señalar que un aumento poblacional en un hábitat con escasos recursos hídricos, como lo es el valle de Azapa, habría gatillado, por una parte, un celo mayor por su control y, por otra, un uso más eficiente de dichos recursos, que podría haber incentivado el proceso de agriculturización regional.

\section{Factores Exógenos}

El proceso de "andinización". Paralelamente a la postura que señala a las poblaciones arcaicas costeras como iniciadoras del proceso agrícola en los valles occidentales, existen autores que dan una gran importancia a la presencia de poblaciones altiplánicas en estos valles como impulsoras de este proceso. Entre esos autores destaca Rivera (1980, 2002), quien ha sostenido y desarrollado la influencia de la tradición andina o altiplánica en los valles occidentales y oasis del extremo norte de Chile, visualizando esta influencia a través del desarrollo de la cultura Alto Ramírez (ca.3000-1200 AP).

Según Rivera, "la fase Alto Ramírez introduce nuevas tecnologías que permiten una producción basada en una agricultura intensiva. Su desarrollo es mucho más complejo y de una naturaleza completamente diferente a los desarrollos culturales que le preceden en la zona" (Rivera 2002: 58).

Cambio climático. Sobre la base de un modelo arqueoclimático, llevado a cabo en las tierras altas (región de Charaña), Ramírez y colaboradores (2001) plantean cambios en la intensidad de las precipitaciones, las que alterarían 
el régimen fluvial de las cuencas cercanas, específicamente el río San José en el valle de Azapa. Los autores señalan que el híper árido medioambiente del norte de Chile se ha mantenido con muy pocos cambios por lo últimos 10.000 años, con casi nulas precipitaciones y temperatura más o menos estables. Entre los 7.000 y 4.000 años AP, la precipitación anual fue alta, mientras que la intensidad de las lluvias fueron relativamente bajas, provocando un flujo del río razonablemente continuo con mayores reservas de agua en los niveles freáticos. Esto creó una condición favorable en las desembocaduras de ríos, con agua fresca, vertientes, áreas pantanosas y un exuberante ecosistema de plantas y animales. (Ramírez et al. 2001: 10). Un ambiente como el señalado fue propicio para el desarrollo de sociedades marítimas asentadas en las desembocaduras de ríos durante casi todo el período Arcaico, tal como sucedió con la cultura Chinchorro en el extremo norte de Chile.

Sin embargo, entre 4000 y $3500 \mathrm{AP}$, una sequía en las alturas, exacerbada por un radical incremento en la intensidad de las precipitaciones, cambió el régimen hidrológico del río San José (valle de Azapa) a una condición cercana a la actual, interrumpiendo el estable ecosistema de desembocaduras de río y conduciendo a las poblaciones costeras a reemplazar su vida marítima por otra de base agrícola (Ramírez et al. 2001: 11).).

En esta misma línea de investigación, Usselmann et al. (1999) y Keefer et al. (1998) señalan que la costa sur peruana no estuvo ajena a fenómenos climáticos durante el Holoceno, incluyendo fenómenos tipo ENSO, caracterizados por lluvias torrenciales y aluviones. Quizás un aspecto que tiene relativa importancia es el fenómeno de incremento de lluvias torreciales que se produce alrededor del 3700$3200 \mathrm{AP}$, justo en el período donde se está produciendo la experimentación de plantas en los valles occidentales. Frente a esta coincidencia nos cabe preguntarnos; ieste fenómeno climático, descrito como "episodio torrencial paroxísmico", que afectó el medio ambiente costero, habría sido una de las causas que motivó al hombre a experimentar con plantas? Pensamos que aún es prematuro analizar esta hipótesis, ya que como lo señala Usselmann et al. (1999), los datos no permiten una reconstrucción fina de los paleoambientes y de las secuencias paleoclimáticas contemporáneas o anteriores. Por otra parte, en los estratos revisados, no se observa ausencia de componen- tes o estratos estériles, lo que hace suponer que el hombre no se habría desplazado a otros ambientes durante esos períodos de incremento de pluviosidad.

\section{* Apropiación y ordenamiento del espacio ocupacional en la costa y VAlle de Azapa}

Con anterioridad, hemos expuesto y caracterizado el territorio que nos interesa y su correspondiente paisaje. Del mismo modo, hemos expuesto a los actores sociales que nos interesan, resaltando rango temporal, espacio geográfico, tipo de asentamiento y la bibliografía respectiva. En este punto, intentaremos una lectura que nos permita conocer sobre la apropiación y ordenamiento del espacio ocupacional utilizado por las sociedades arcaicas y formativas del extremo norte de Chile.

Durante todo el período Arcaico, los asentamientos humanos se situaron en torno al litoral, fuente permanente de alimentos, ya sea en la costa rocosa al sur de la ciudad de Arica o en la costa arenosa (playas) hacia el norte de esta cuidad. No obstante el hecho que sus asentamientos permanentes estuviesen ubicados en el litoral, existen antecedentes dispersos que señalan que estos pescadores utilizaban también los espacios interiores del valle. Tal es el caso del sitio Acha 2, que representa un campamento de pescadores ubicado $5 \mathrm{~km}$ valle adentro en Azapa (Muñoz 1993; Muñoz y Chacama 1993, 1997; Muñoz y Arriaza 2006; Chacama y Muñoz 2001) o Conanoxa, a $40 \mathrm{~km}$ del mar en el valle de Camarones (Schiappacasse et al. 1993), entre otros.

Lo anterior nos presenta a las sociedades de pescadoresrecolectores obteniendo su principal fuente de recursos en el litoral del Pacífico, pero complementado por el manejo de recursos provenientes de otros nichos ecológicos. Sabemos que estas poblaciones, por su número, pudieron haber estado organizadas en pequeños bandos, que pudieron estar vinculados a espacios o cotos de pesca restringidos, como pequeñas caletas ubicadas en la costa rocosa. Podríamos señalar también que un ordenado manejo territorial les permitía acceder a los bivalvos y peces de las playas arenosas, a los crustáceos y peces de rocas $y$, además, acceder en los valles a fibras vegetales y materias primas líticas para la confección de instrumental de pesca. 
Los antecedentes disponibles -si bien aún escasos-, nos permiten una lectura adicional del manejo que estas poblaciones de pescadores arcaicos hicieron del territorio, sin duda orientado por el paisaje y sus recursos. Este manejo territorial nos presenta una franja de extracción de recursos, ubicada entre la baja y la alta marea, ya sea en costa rocosa o en las playas de arena, y una franja en cotas más elevadas a media ladera de la cordillera de la Costa, utilizada para instalar campamentos rudimentarios (Muñoz y Chacama 1982, 1997). En la misma franja de los campamentos, es decir a media ladera, se sitúan los espacios ceremoniales-mortuorios (cementerios), p.e. Quiani 7 (Dauelsberg 1974), Morro I (Standen 1991), Morro 1/6 (Focacci y Chacón 1989) y Morro 1/5 (Guillén 1995). Entre ambas franjas, se despliegan a lo largo de todo el litoral espacios utilizados para la faena de moluscos y peces, conocidos como concheros o conchales (Bird 1943). Éstos llegan a conformar elevados montículos producto de cientos y miles de años de uso continuo. Resumiendo lo hasta aquí señalado, podríamos visualizar dos grandes franjas o estados de ocupación: la primera, el litoral mismo y su entorno donde se ubica toda la actividad extractiva y de faena; y la segunda, a media ladera, donde se ubican las "habitaciones" de los vivos y los muertos (cementerios).

Otro nivel de ordenamiento del espacio territorial debiera corresponder a sectores bien definidos y, si se nos permite trasladar la lógica visualizada en los documentos coloniales y en las sociedades andinas contemporáneas, éstos debieran estar pormenorizados y nombrados. Las pequeñas caletas con sus respectivos conchales, zonas de campamentos y espacios mortuorios debieran ser, hoy en día, los elementos visibles que nos permitan visualizar a las pequeñas bandas de pescadores-recolectores, con sus respectivos cotos de caza. Vistas las cosas de esa manera, el litoral durante todo el período Arcaico, incluido el período Arcaico Tardío, estuvo organizado con sus respectivas designaciones en segmentos definidos en gran medida por los recursos naturales y la conformación geográfica de la zona.

Más allá de estos espacios ordenadores, nos encontramos con otros hitos, como los espacios de función cúltica que presumimos también fueron ordenadores del espacio ocupado. Tal es el caso de la cueva de la Capilla, ubicada en pleno litoral rocoso a $5 \mathrm{~km}$ al sur de la ciudad de Arica. Esta cueva, en cuyas paredes se hallan una serie de pictografías, presentó un inusual hallazgo de aproximadamente 50 faldellines en $20 \mathrm{~m}^{2}$ de excavación, confeccionados con fibra vegetal, algunos con señas de uso y otros sin uso aparente e intencionalmente enterrados en el piso estéril. Unida al hallazgo de osamentas humanas, pinturas rupestres y al hecho de tratarse de un espacio cerrado (cueva), esa situación nos sugiere que allí se pudo haber celebrado ceremonias relacionadas con el cambio de vestimenta (Muñoz y Chacama 1982; Chacama y Muñoz 1991).

Otros espacios articuladores corresponderían a hitos geográficos de cierta relevancia. Uno de ellos es un corredor natural que une el valle de Azapa y el litoral rocoso a la altura del área de caleta Quiani, que termina en lo que hoy es una aguada fósil ubicada en la vertiente occidental de la cordillera de la Costa. Este corredor natural da origen a una pequeña quebradilla que termina en una estrecha playa de arena en medio de la costa rocosa del sector, en torno a la cual se ubican todos los sitios designados con la sigla Qui. (Quiani). En su extremo opuesto, este corredor termina en lo que hoy es el aeropuerto militar "El Buitre", justo en el sector en que el valle de Azapa confluye con uno de sus tributarios importantes, la quebrada de Acha, lugar donde se encuentran los sitios arcaicos de Acha 2 (Muñoz y Chacama 1993) y Acha 3 (Nueva Esperanza) (Standen y Santoro 2004). El mencionado corredor es propiamente un conector entre dos áreas geográficas relevantes, el valle y la costa.

Otro espacio relevante que surge de este análisis es el peñón rocoso conocido como morro de Arica, que constituye el punto de separación o de articulación entre la costa rocosa y la costa de arena. El morro de Arica está conformado por las últimas estribaciones de la cordillera de la Costa, así como también es el tramo final de la ladera sur del valle de Azapa. En ese punto, ambas formaciones confluyen y se articulan. Pero, más allá de estas características geográficas, ese peñón rocoso sirvió como abrigo a las poblaciones Chinchorro agrupadas en la desembocadura del valle de Azapa, las que depositaron en sus faldeos, desde al menos 8.000 años antes del presente, los cuerpos momificados de sus muertos. En dichos términos, el morro de Arica debió constituir algo similar a una huaca del período Arcaico, la cual recibió por milenios los cuerpos de sucesivas poblaciones. 
Los señalados aspectos de este hito geográfico debieron darle la connotación de un espacio de culto que pudo haber actuado como un poderoso referente ordenador del espacio desde el remoto pasado y, por qué no, hasta nuestro días.

A medida que los siglos fueron transcurriendo, se observa un notorio desplazamiento de las poblaciones de pescadores-recolectores hacia los valles fértiles, en este caso hacia el valle de Azapa. Habíamos mencionado con anterioridad que, a partir de algunas evidencias disponibles, sabíamos que las sociedades arcaicas con asentamientos permanentes en el litoral se desplazaban ocasionalmente hacia los valles en busca de materias primas y algunos complementos para su dieta (Muñoz y Chacama 1982; Arriaza 1995; Muñoz 1995; Chacama y Muñoz 2001; Muñoz y Arriaza 2006) (Figura 4). Dicho proceso continuó con el tiempo con la diferencia que, a medida que se avanzaba con la experimentación agrícola, los asentamientos de valle se comenzaron hacer permanentes, comenzando un proceso de sedentarización en torno a potenciales recursos hídricos (vertientes) con sus respectivas tierras de cultivos.

Alrededor de los inicios de nuestra era, el cambio del eje poblacional desde la costa hacia los valles se profundizaba más; en cada lugar con potenciales recursos hídricos, conocidos como palca (confluencias de ríos), se instalaron los pescadores para desarrollar una incipiente agricultura. En el caso del río San José, valle de Azapa, los lugares escogidas fueron las terrazas de Pampa Alto Ramírez y San Miguel de Azapa, donde se hallaban los mayores recursos de agua de vertientes. Esta situación habría permitido que se comenzara a percibir el orden del espacio ocupado. Un claro ejemplo de ello se presenta en la Pampa Alto Ramírez, en la cual se registró la existencia de la única aldea formativa reportada hasta hoy dentro del área que nos compete: Azapa 83 (Rivera 1987). Cercano a dicha aldea, se encuentra el cementerio de agricultores tempranos Az 14 (Santoro 1980b) y varios sitios con concentraciones de túmulos ( $\mathrm{Az}$ 17, 80, 84, 86 y 122), muchos de ellos con más de treinta de estas estructuras, lo que le da una particular connotación al área en cuestión (Muñoz y Gutiérrez 2011).

Con anterioridad, señalábamos que las sociedades costeras del arcaico, a partir de la concentración de recur- sos hídricos y alimentarios, ocuparon dichos espacios instalando en ellos sectores de faena, habitacionales y mortuorios, y que dichos conglomerados podrían haber jalonado toda la costa a su largo, sectorizando, nombrándolo y en definitiva ordenando la percepción del espacio costero y su territorio. Si hacemos una analogía con lo ocurrido con las sociedades costeras, tendríamos que los agricultores tempranos, a partir de recursos hídricos disponibles, fueron cultivando ciertos productos agrícolas, lo que les permitió instalar sus viviendas y construir los túmulos, generando complejos asentamientos humanos que fueron jalonando el valle desde la costa hasta unos $20 \mathrm{~km}$ valle adentro.

Visualizando dichos asentamientos humanos en tiempos prehispánicos, veríamos un paisaje pedregoso con un conjunto de oasis dentro de zonas de confluencia entre el río San José y sus tributarios, con sus respectivos ojos de agua. Aunque todavía no tenemos respuesta sobre la organización social imperante en este conjunto de asentamientos, podríamos a priori suponer que cada uno de ellos tendría su propia estructura organizacional; de ser así, cada uno de estos conglomerados actuaría también como un sistema ordenador del valle en su conjunto. Considerando que los diferentes sectores son de distinta envergadura, el sistema presentaría asentamientos de disímil jerarquía. En principio, el área ya descrita de Pampa Alto Ramírez correspondería a un área de mayor jerarquía. Otra sería el área del actual poblado de San Miguel de Azapa, donde se sitúa el complejo de túmulos de Az 7o. A la inversa, el conjunto de túmulos de cerro Sombrero y Buen Retiro (quebrada del Diablo) posiblemente correspondieron a conjuntos menores. Los conjuntos de túmulos que fueron construidos en estas áreas de mayor jerarquía presentan una alta visibilidad que incluye la costa de Arica hasta el encajonamiento del valle a la altura del kilómetro 25 . El dominio visual permitió a las poblaciones formativas posiblemente calcular el tiempo y distancia de un complejo funerario a otro, así como conocer los recursos vegetales y faunísticos que cada humedal y vertiente ofrecían. Su construcción al parecer fue resultado de la organización y planificación social que las poblaciones formativas hicieron del espacio ocupado. La determinación de construir monumentos de forma monticular pudo ser una estrategia de la sociedad Alto Ramírez, tomando como modelo la figura del cerro, que habría 


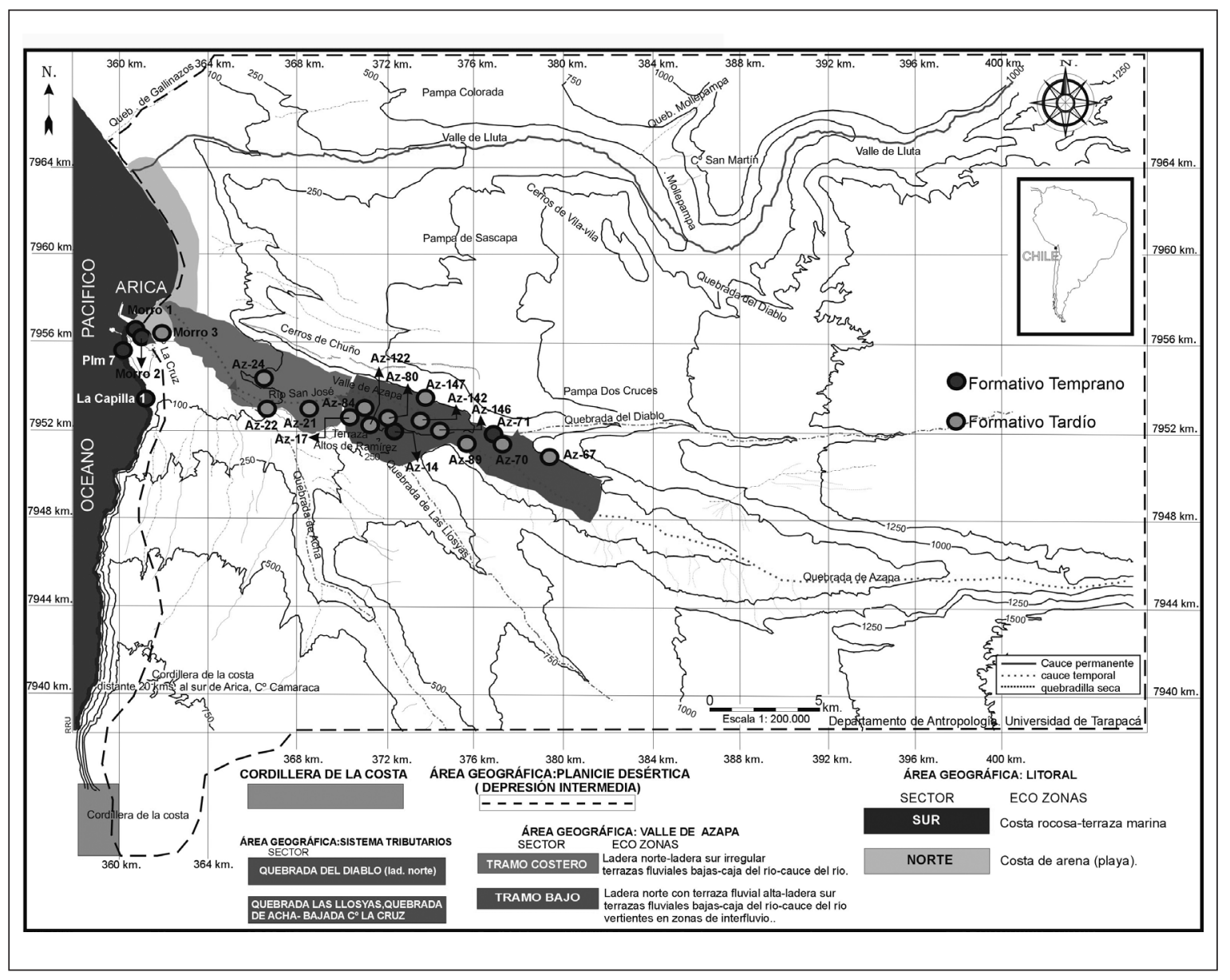

Figura 4. Sitios del período Formativo Temprano y Tardío y su distribución espacial.

constituido las deidades tutelares relacionadas con el mito de origen de estas poblaciones (Muñoz y Gutiérrez 2011).

En resumen, podemos visualizar que las poblaciones de agricultores iniciales tuvieron una percepción del valle de Azapa a partir de los recursos hídricos disponibles. Inicialmente, las poblaciones debieron haber manejado sincrónicamente tanto los espacios de costa como los espacios de valle, quizás con campamentos más permanentes en la zona de costa, realizando esporádicas incursiones hacia el valle. No obstante y a medida que el proceso agrícola fue teniendo éxito, estas incursiones temporales se hicieron permanentes, llegando a desarrollar asentamientos complejos y multicomponentes. Por las características paisajísticas del valle en épocas prehis- pánicas y por la distribución de los recursos hídricos en él, los mencionados asentamientos humanos estuvieron jalonados y distantes unos de otros. Dicha distribución espacial nos sugiere la forma de ordenamiento y uso del espacio por parte de estas poblaciones, cada una de ellas con su propia estructura organizacional y con sus respectivos centros ceremoniales (túmulos funerarios). En segundo término, este orden de cosas estuvo diferenciado con puntos de mayor jerarquía respecto de otros menores. En ese aspecto, San Miguel, Alto Ramírez y, en menor escala, AZ-67 y cerro Moreno, son coincidentes con los espacios de mayor proliferación de vertientes. Es a partir de estos núcleos de agricultores tempranos y su ordenamiento territorial del espacio, desde donde se gesta todo el orden aldeano que continuó en el valle en los siglos posteriores (Figura 4). 
Iván Muñoz O., Juan Chacama R.

\begin{tabular}{|c|c|c|c|c|c|}
\hline \multicolumn{6}{|c|}{ PERÍODO ARCAICO TARDÍO } \\
\hline Núm. de sitios: 4 & Dataciones & Características culturales & $\begin{array}{c}\text { Hábitat y } \\
\text { asentamientos }\end{array}$ & $\begin{array}{c}\text { Explotación de } \\
\text { recursos naturales }\end{array}$ & $\begin{array}{c}\text { Espacios } \\
\text { complementarios }\end{array}$ \\
\hline Quiani 7 & $\begin{array}{l}1600 \text { AC Nivel } \\
\text { temprano }\end{array}$ & \multirow{3}{*}{$\begin{array}{c}\text { Cuerpos con las piernas } \\
\text { estiradas sin momificación. } \\
\text { Cuerpos en posición decúbito } \\
\text { dorsal con las piernas } \\
\text { flexionadas. } \\
\text { Productos vegetales: algodón, } \\
\text { camote, calabaza y mandioca. } \\
\text { Decoración geométrica en } \\
\text { tejidos, cestería y calabazas. } \\
\text { Tubos y espátulas para inhalar } \\
\text { substancias psicotrópicas. } \\
\text { Adornos: collares, turbantes de } \\
\text { lana, tocado cefálico. }\end{array}$} & \multirow[b]{3}{*}{$\begin{array}{l}\text { Terrazas y faldeos de } \\
\text { cerros, formación de } \\
\text { basurales asociados a } \\
\text { espacios de entierros } \\
\text { en fosas. } \\
\text { Usos de espacios } \\
\text { cerrados (cueva) para } \\
\text { ceremonias. }\end{array}$} & \multirow{3}{*}{$\begin{array}{l}\text { Humedales de la } \\
\text { desembocadura } \\
\text { del río San José, } \\
\text { vertientes de Quiani } \\
\text { y sector de playa } \\
\text { Chinchorro, La } \\
\text { Chimba. }\end{array}$} & \multirow[b]{3}{*}{$\begin{array}{l}\text { Vertientes y humedales } \\
\text { del valle de Azapa: } \\
\text { explotación de recursos } \\
\text { vegetales, recolección de } \\
\text { camarones, caza menor. }\end{array}$} \\
\hline Morro $1 / 6$ y $1 / 5$ & $2300 \mathrm{AC}-800 \mathrm{AC}$ & & & & \\
\hline La Capilla 1, cueva & $\begin{array}{c}1700 \text { AC Nivel } \\
\text { temprano (comienzo } \\
\text { de ocupación) }\end{array}$ & & & & \\
\hline
\end{tabular}

Tabla 5. Resúmenes de Indicadores para el período Arcaico Tardío.

\begin{tabular}{|c|c|c|c|c|c|}
\hline \multicolumn{6}{|c|}{ FORMATIVO TEMPRANO } \\
\hline $\begin{array}{l}\text { Núm. de sitios } \\
\text { y complejos de } \\
\text { túmulos: } 7\end{array}$ & Dataciones & Características culturales & $\begin{array}{c}\text { Hábitaty } \\
\text { asentamientos }\end{array}$ & $\begin{array}{l}\text { Explotación de } \\
\text { recursos naturales }\end{array}$ & $\begin{array}{c}\text { Espacios } \\
\text { complementarios }\end{array}$ \\
\hline Playa Miller-7 & $500 \mathrm{AC}$ & \multirow{7}{*}{$\begin{array}{l}\text { Entierros en fosas y túmulos. El cuerpo } \\
\text { está depositado en posición decúbito } \\
\text { dorsal o lateral con las piernas. } \\
\text { Instrumentos agrícolas: palos con } \\
\text { puntas aguzadas. Cultivos de maíz, ají, } \\
\text { camote, quinua, jíquima, poroto, pallar. } \\
\text { Tiestos de cerámica de forma globular } \\
\text { (ollas) de manufactura tosca. } \\
\text { Prendas de vestir confeccionadas } \\
\text { en lana, con motivos geométricos. } \\
\text { Presencia de turbantes y bolsas para } \\
\text { guardar implementos tecnológicos. } \\
\text { Objetos confeccionados en metales } \\
\text { (cobre). Cucharas y figura de forma } \\
\text { serpenteada. }\end{array}$} & \multirow{7}{*}{$\begin{array}{c}\text { Lugares de amplia } \\
\text { visibilidad cercanos a } \\
\text { vertientes. } \\
\text { Ocupación humana } \\
\text { de las terrazas } \\
\text { fluviales: espacios } \\
\text { habitacionales y de } \\
\text { cementerios. }\end{array}$} & \multirow{7}{*}{$\begin{array}{c}\text { Vertientes y } \\
\text { humedales del valle } \\
\text { de Azapa para la } \\
\text { obtención de los } \\
\text { recursos vegetales, } \\
\text { recolección de } \\
\text { camarones y caza } \\
\text { menor. } \\
\text { Afloramientos de } \\
\text { cuarcita y canteras } \\
\text { de arcilla, obtención } \\
\text { de cantos rodados } \\
\text { de río. }\end{array}$} & \multirow{7}{*}{$\begin{array}{c}\text { Humedales de la } \\
\text { desembocadura del río } \\
\text { San Jose, humedales de la } \\
\text { franja costera, la Chimba. } \\
\text { Playas rocosas y arenosas. } \\
\text { Pesca, caza y recolección } \\
\text { marina, litoral de Arica. }\end{array}$} \\
\hline Morro 2/2 y 5 & $800 \mathrm{AC}$ & & & & \\
\hline Az-71 (Nivel Bajo) & $900 \mathrm{AC}$ & & & & \\
\hline Az-14 (Nivel Bajo) & $600 \mathrm{AC}$ & & & & \\
\hline $\begin{array}{c}\text { Complejo de } \\
\text { Túmulos AZ-148, } \\
\text { Peroque (Azapa) } \\
\text { Nivel Bajo }\end{array}$ & $500 \mathrm{AC}$ & & & & \\
\hline $\begin{array}{c}\text { Complejo de } \\
\text { Túmulos Az-67 } \\
\text { (Azapa) Nivel Bajo }\end{array}$ & $840 \mathrm{AC}$ & & & & \\
\hline $\begin{array}{c}\text { Complejo de } \\
\text { Túmulos Az-12 } \\
\text { (Azapa) Nivel Bajo }\end{array}$ & $470 \mathrm{AC}$ & & & & \\
\hline
\end{tabular}

Tabla 6. Resúmenes de Indicadores para el período Formativo Temprano. 


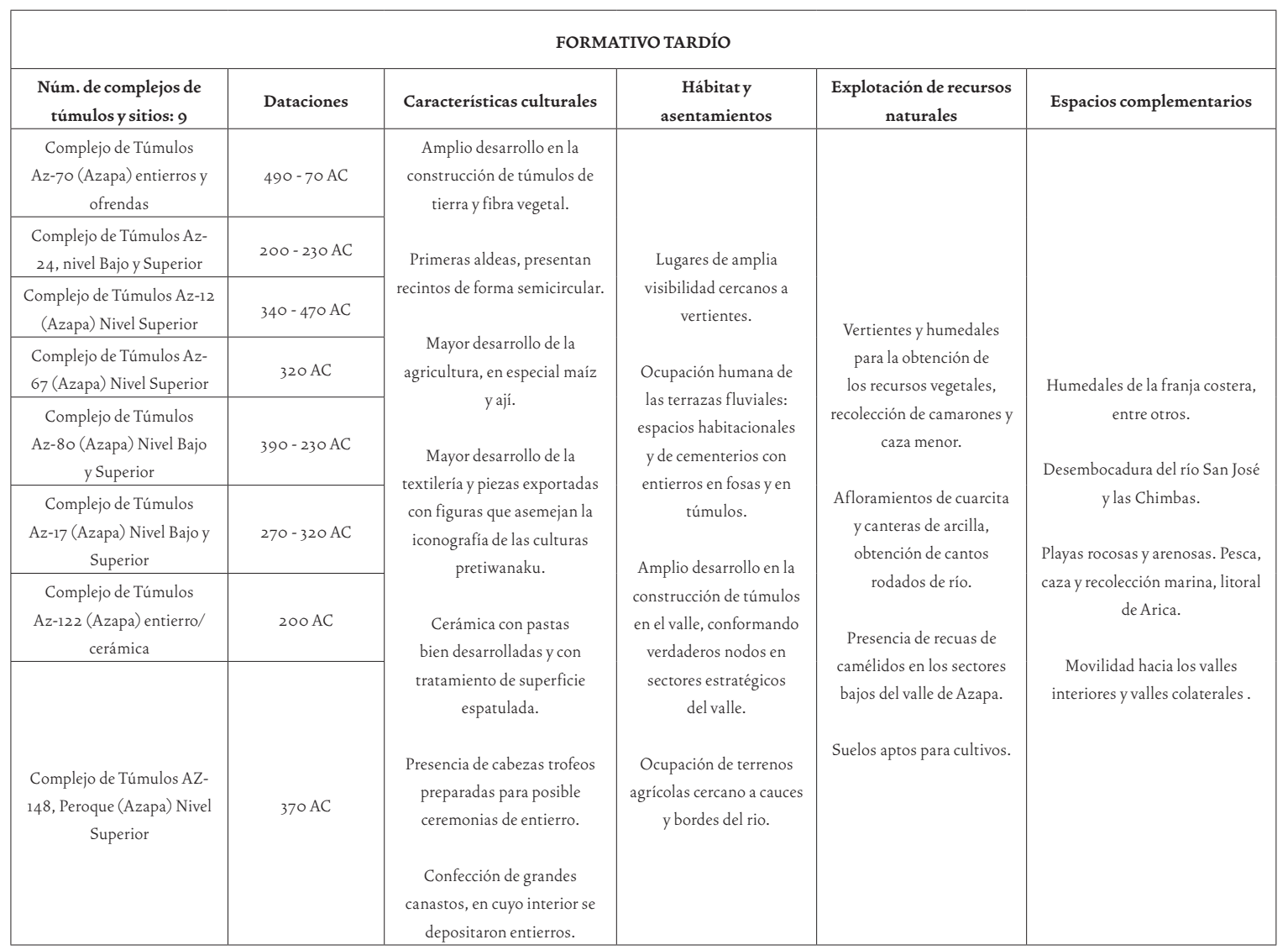

Tabla 7. Resúmenes de Indicadores para el período Formativo Medio.

\section{* Comentarios finales}

La información que nos han arrojado las prospecciones y excavaciones realizadas en la costa de Arica y en el tramo bajo del valle de Azapa, nos permite reflexionar en torno a que, para entender el proceso de transición del período Arcaico al Formativo, es importante conocer el paisaje social y natural que caracterizó dicho proceso. La combinación de ambos permitió un singular desarrollo cultural a escala en un particular escenario, como fue el desierto costero de Atacama, en este caso la zona de Arica, dándose paralelamente un desarrollo cultural tanto en la costa como en su valle más cercano, Azapa. Sin embargo, los actores sociales de este proceso al parecer fueron los mismos: pescadores-recolectores con una larga tradición cultural, que adoptaron en determinado momento prácticas agrícolas. Pensamos que más que una secuencia de hechos producidos entre $1500 \mathrm{AC}$ y $500 \mathrm{DC}$, este pro- ceso social fue producto de una intensa interrelación del paisaje cultural y natural. La información registrada nos lleva a un escenario mucho más dinámico, con raíces antiguas, en la cual cada logro alcanzado a nivel de infra y superestructura se fue integrando, al punto que habrían sido los mismos pescadores los que se habrían comprometido en impulsar en forma paulatina la explotación del valle, sin dejar de lado la producción marina en términos de pesca, caza y recolección (Tabla 5, 6 y 7).

Un valle domesticado desde el punto de vista agrícola, con un poblamiento aldeano estable es el escenario con que al parecer se encontraron las poblaciones altiplánicas pretiawanaku al conectarse con los valles de Arica, en lo que hemos llamada fase Alto Ramírez. Por lo tanto, su aporte no habría estado en la organización de una nueva línea productiva económica, sino que más bien habrían aprovechado la producción agrícola dentro de 
las relaciones de intercambio. Es en este contexto al parecer donde se habrían tranzado objetos y piezas novedosas que expresan la clásica iconografía escalerada, representaciones en torno al culto al sacrificador y figuras naturalistas que hemos vinculado con los grupos altiplánicos (Muñoz 1989).

Finalmente el análisis y discusión presentado en este artículo sobre la transformación del paisaje social de los pescadores arcaicos a agricultores incipientes, en Arica, ratifica la hipótesis planteada en publicaciones anteriores (Muñoz 2004), donde los actores sociales clave para alcanzar el desarrollo agrícola fueron los pescadores de historia milenaria.

Agradecimientos Este artículo es resultado del proyecto FONDECYT 1085106. Se agradece al Sr. José Rocha por el material gráfico y fotográfico utilizado en este trabajo y el apoyo del Convenio de Desempeño Universidad de Tarapacá-Mineduc.

\section{* Referencias citadas}

ARRIAZA, B., 1995. Beyond Death: The Chinchorro Mummies of Ancient Chile. Smithsonian Institution Press, Washington D.C.

BIRD, J., 1943. Excavations in Northern Chile. Anthropological Papers, American Museum of Natural History, vol. 38, New York

BOURDIEU, P., 1999. Intelectuales, política y poder. Eudeba, Buenos Aires.

CHACAMA, J., y I. MUÑOZ, 1991. La cueva de la Capilla: Manifestaciones de arte y símbolos de los pescadores arcaicos de Arica. Actas del XI Congreso Nacional de Arqueología Chilena: 37-41. Museo Nacional de Historia Natural, Sociedad Chilena de Arqueología, Santiago.

2001. Patrón funerario Pre Chinchorro en un contexto de semi nomadismo y complementariedad ecológica. El sitio Acha-2, Extremo norte de Chile, ca. 9.500-10.000 años AP. Chungara 33 (1): 51-54.

2012 Ms. De pescadores a agricultores: En torno al proceso de cambio cultural en el extremo norte de Chile. Manuscrito presentado en el XVIII Congreso de arqueología Chilena.

CRIADO, F., 1999. El terreno al espacio: planteamientos y perspectivas para la arqueología del Paisaje. Editado por Capa 6. Grupo de investigación en arqueología del Paisaje. Universidad de Santiago de Compostela, Santiago de Compostela.

DAGNINO, V., 1909. El corregimiento de Arica. Imprenta la época, Arica.

DAUELSBERG, P., 1974. Excavaciones arqueológicas en Quiani (Provincia de Tarapacá Departamento de Arica). Chungara 4: 61-63.
1985. Faldas del Morro: Fase Cultural Agroalfarera Temprana. Chungara 14: 7-44.

FOCACCI, G., 1974. Excavaciones en Playa Miller 7, Arica (Chile). Chungara 3: 23-74.

1983. El Tiwanaku clásico en el valle de Azapa. Documento de Trabajo 3. Universidad de Tarapacá, Arica.

FOCACCI, G., y S. ERICES, 1972-1973. Excavaciones en túmulos de San Miguel de Azapa (Arica-Chile). Actas del VI Congreso de Arqueología Chilena: 47-62. Universidad de Chile, Santiago.

FOCACCI, G., y S. CHACÓN, 1989. Excavaciones arqueológicas en los faldeos del Morro de Arica sitios Morro $1 / 6$ y 2/2. Chungara 22: 15-62.

GUILLÉN, S., 1995. Morro 1/5 (Arica): Momias y cráneos para discutir el origen y la naturaleza de la cultura Chinchorro. Hombre y Desierto 9: 55-64.

KEEFER, D., S. DE FRANCE, M. MOSELEY, J. RICHARDSON IIII, D. SATTERLEE y A. DAY-LEWIS, 1998. Early Maritime Economy and El Niño Events at Quebrada Tacahuay, Perú. Science 281: 1833-1835.

KELLER, C., 1946. El Departamento de Arica. Editorial Zig-Zag, Santiago.

MUÑOZ, I., 1980. Investigaciones arqueológicas en los túmulos funerarios del valle de Azapa. Chungara 6: 57-95.

1982. Las sociedades costeras en el litoral de Arica durante el período Arcaico Tardío y sus vinculaciones con la costa peruana. Chungara 9: 134-136. 
1983. Fase Alto Ramírez en los valles del extremo norte de Chile. Documentos de Trabajo 3. Universidad de Tarapacá. Arica, Chile.

1985. Enterramientos en túmulos en el valle de Azapa: Nuevas evidencias para definir la fase Alto Ramírez en el extremo norte de Chile. Chungara: 19: 93-128.

1986. Aportes a la reconstitución histórica del poblamiento aldeano en el valle de Azapa (Arica-Chile). Chungara 16-17:307322.

1989. El Período Formativo en el Norte Grande (100 a.C. a 500 d. C.). En Culturas de Chile. Prehistoria. Desde sus orígenes hasta los albores de la Conquista, pp. 107-128. Editorial Andrés Bello, Santiago.

1993. Spatial dimensions of complementary resource utilization at Acha 2 and San Lorenzo. En Domestic Architectura, Ethnicity and Complementary in the South Central Andes, M. Aldenderfer (Ed.), pp. 94-102. Iowa Press, Iowa.

1995. El poblamiento prehispánico costero en la costa de Arica y desembocadura del río Camarones. Actas del XIII Congreso Nacional de Arqueología Chilena, tomo I: 3- 28. Sociedad Chilena de Arqueología, Antofagasta.

1995-96. Poblamiento humano y relaciones Interculturales en el valle de Azapa: Nuevos hallazgos en torno al período Formativo y Tiwanaku. Diálogo Andino 14-15: 241-278.

2004. Estrategias de organización prehispánicas en Azapa: el Impacto de la agricultura en un valle del desierto costero del Pacífico. Ediciones Universidad de Tarapacá, Arica.

2010. Explotación de los ecosistemas húmedos por los tempranos agricultores prehispánicos del valle de Azapa. Idesia 28 (2): 107-115.

2011. Persistencia de la tradición pescadora recolectora en la costa de Arica: Identificación de rasgos culturales y discusión sobre su alcance en el contexto de las poblaciones agrícolas tempranas. Chungara 43: 1469-485.

MUÑOZ, I., y B. ARRIAZA, 2006. Momificación artificial y patrón de residencia de las poblaciones Chinchorro. El hombre temprano en América y sus implicaciones en el poblamiento de la cuenca de México. Colección científica Primer Simposio Internacional, 107-144. INAH, Ciudad de México.

MUÑOZ, I., y J. CHACAMA, 1982. Investigaciones arqueológicas en las poblaciones precerámicas de la costa de Arica. Documentos de Trabajo 2. Universidad de Tarapacá, Arica.
1993. Patrón de asentamiento y cronología de Acha-2. En Acha $2 y$ los orígenes del poblamiento humano en Arica, I. Muñoz, B. Arriaza y M. Aufderheide (Eds.), pp. 21-46. Ediciones Universidad de Tarapacá, Arica.

1997. Acha-2, 9.000 años de tradición pescadora-recolectora en el norte de Chile. En Saberes y Memorias en los Andes, T. Bouysse-Cassagne (Ed.), pp. 21-39. Instituto de Estudios Andinos, París.

MUÑOZ, I., y M. GUTIÉRREZ, 2011. Los túmulos de cerro Moreno: Arquitectura en armonía con el paisaje desértico, período agrícola temprano, valle de Azapa, norte de Chile. Anales XXIV, Reunión Anual de Etnología, La Paz, Bolivia: 163-78.

MUÑOZ, I., y F. ZALAQUETT, 2011. El paisaje en la distribución de los túmulos funerarios del valle de Azapa, durante el período formativo, norte de Chile. Revista de Geografía Norte Grande 50: 23-43.

MUÑOZ, I., yJ. ROCHA, 2012 Ms. Nuevas dataciones de radiocarbono para los túmulos funerarios del valle de Azapa: Discusión en torno a la cronología de túmulos y la antigüedad del proceso Formativo en Arica. Manuscrito presentado en el IVCongreso Argentino de Arqueometría, Lujan, Buenos Aires.

NÚÑEZ, L., 1969. Sobre los complejos culturales Chinchorro y Faldas del Morro. Rehue 2: 111-142.

NÚÑEZ, L., 1983. Paleoindio y Arcaico en Chile. Diversidad, Secuencia y proceso. Series Monografías 3. Ediciones Cuicuilco, Ciudad de México.

NÚÑEZ, L., 1989. Hacia la producción de alimentos y la vida sedentaria (5.000 a.C. a 900 d.C.). En Prehistoria de Chile. Desde sus orígenes hasta los albores de la Conquista, J. Hidalgo, V. Schiappacasse, H. Niemeyer, C. Aldunate e I. Solimano (Eds.), pp. 81-106. Editorial Andrés Bello, Santiago.

NÚÑEZ, L., y C. SANTORO, 2011. El tránsito Arcaico-Formativo en la Circumpuna y valles occidentales del centro sur andino: Hacia los cambios "Neolíticos". Chungara 43: 487-530.

RAMÍREZ, L. M., R. U. BRYSON y R. A. BRYSON, 2001. Paleoclimatic and material cultural perspective on the Formative period of northern Chile. Chungara (33) 1: 5-12.

RIVERA, M., 1980. Algunos fenómenos de complementariedad económica, a través de los datos arqueológicos en el área centro sur andina. La fase Alto Ramírez reformulada. Estudios Arqueológicos, Número Especial: 71-103.

1987. Tres fechados radiométricos de Pampa Alto Ramírez, Norte de Chile. Chungara 18: 7-13. 
1994. Hacia la complejidad social y política: El desarrollo Alto Ramírez del norte de Chile. Diálogo Andino 13: 9-38.

1995-96. En torno a los orígenes de las sociedades complejas andinas: excavaciones en Ramaditas, una aldea formativa del desierto de Atacama, Chile Diálogo Andino 14-15: 205-240.

2002. Historias del desierto. Arqueología del norte de Chile. Editorial del Norte, La Serena.

ROMERO, A., C. SANTORO, D. VALENZUELA, J. CHACAMA, E. ROSSELLO y L. PIACENZA, 2004. Túmulos, ideología y paisaje de la fase Alto Ramírez del valle de Azapa. Chungara 36: 261-272.

ROTHHAMMER, F., y C. SANTORO, 2001. El desarrollo cultural en el valle de Azapa, extremo norte de Chile y su vinculación con los desplazamientos poblacionales altiplánicos. Latin American Antiquity 12 (1): 59-66.

SANTORO, C., 1980a. Estratigrafía y secuencia cultural funeraria fases Azapa, Alto Ramirez y Tiwanaku. Chungara 6: 24-45.

1980b. Fase Azapa, transición del Arcaico al desarrollo agrario inicial en los valles bajos de Arica. Chungara 6: 46-56.

1982. Formativo temprano en el extremo norte de Chile. Chungara 8:33-62.

2000. Formativo en la región de valles occidentales del área centro sur andina. En Formativo Sudamericano, una Revaluación, P. Lederberger (Ed.), pp. 243-254. Editorial Abya-Yala, Quito.

STANDEN, V., 1991. El cementerio Morro-1: Nuevas evidencias de la tradición funeraria Chinchorro (Período Arcaico, norte de Chile). Tesis de Magíster. Pontificia Universidad Católica del Perú, Lima.
STANDEN, V., y C. SANTORO. 2004. Patrón funerario arcaico temprano del sitio Acha-3 y su relación con Chinchorro: Cazadores, pescadores y recolectores de la costa norte de Chile, Latin American Antiquity 15 (1): 89-109.

STANDEN, V., B. ARRIAZA, Á. ROMERO, y C. SANTORO, 2007. Violencia letal y conflictos intergrupales en el Formativo del valle de Azapa, norte de Chile. Andes 7: 11-23.

SCHIAPPACASSE, V., J. CHACAMA, I. MUÑOZ y H. NIEMEYER, 1993. Dispersión del depósito arqueológico en un yacimiento de recolectores arcaicos, con énfasis en el microdepósito. Actas del XII Congreso Nacional de Arqueología Chilena, tomo I: 1-24. Sociedad Chilena de Arqueología, Santiago.

SUTTER, R., 2000. Prehistoric genetic and cultural change: a bioarcheological search for pre-Inka altiplano colonies in the coastal valleys of Moquegua, Peru and Azapa, Chile. Latin American Antiquity 11: 43-70.

2006. Modelos alternativos para explicar el doblamiento prehistórico del valle de Azapa, norte de Chile, mediante análisis de correlación de matrices. Chungara 38 (1): 63-82.

TAPIA, A., 2012 Ms. El valle de Azapa: Marco geográfico natural. Manuscrito. Informe Final. FONDECYT 1985106.

USSELMANN, P., M. FOTUGNE, D. LAVALLEE, M. JULIEN, y C. HATTE, 1999. Estabilidad y rupturas dinámicas en el Holoceno de la costa sur peruana: el valle de la quebrada de los Burros (Departamento de Tacna). Bulletin de I'Institut Francais d'Ëtudes Andines 28 (1): 1-11.

VÁSQUEZ DE ESPINOZA, A., 1969 [1628-29]. Compendio y descripción de las Indias Occidentales. Biblioteca de Autores Españoles, tomo CCXXXI. Atlas, Madrid. 